\title{
Students' Expectations and Perceptions on Service Quality of E-Learning in a Selected Faculty of a Public University in Malaysia
}

\author{
Chen Yan Li \\ Universiti Putra Malaysia, Serdang, Malaysia \\ onteause@yahoo.com
}

\author{
Soaib Asimiran \\ Universiti Putra Malaysia, Serdang, Malaysia \\ soaib@upm.edu.my
}

\author{
Suyitno \\ Universitas Gresik \\ onteause@yahoo.com
}

\begin{abstract}
The main purpose of this quantitative research is to examine students' expectations and perceptions on the service quality of e-learning in a selected faculty of a public university in Malaysia. Data for the research are collected through a survey on sixth semester undergraduate students in one of the faculties in a public university. Questionnaire is adopted based on Parasuraman's (1994) SERVQUAL model which includes five dimensions: reliability, responsiveness, empathy, tangibility and assurance. Descriptive analysis is conducted to indicate the level of students' expectations and perceptions on service quality of e-learning as well as the gap between their expectations and perceptions. Paired t-test analysis is performed to test the significant difference between students' expectations and perceptions. The findings indicate that the level of students' expectations is high with tangibility regarded as the highest amongst the five domains examined. However, the level of students' perceptions is medium. Among the five dimensions, the level of perception towards assurance is the highest, while the level of perception towards empathy is the lowest. There exists a gap between students' expectations and students' perceptions. Paired ttest shows that there is a significant difference between students' expectations and perceptions indicating students are not highly satisfied with the service quality of e-earning provided by the selected university. Further initiatives should be taken by the university to improve the service quality of the e-learning facilities focusing on areas identified in the findings.
\end{abstract}

Keywords: e-learning, service quality, expectation, perception, satisfaction

\section{INTRODUCTION}

Institutions of higher learning have been introducing academic programs which are inclined towards using internet based resources (Ally, 2004; Kim \& Bonk, 2008). This is a result of the development of computer and internet in the $21^{\text {st }}$ century. Learning via electronic means or rather elearning has become a very common feature in higher educational institutions. With the development of elearning, a student-centered learning and a more flexible approach to learning are created. In Malaysian higher education institutions, the usage of computer has enhanced the effects on students' teaching and learning. E-learning has been used as a tool to improve learning among students and boost the quality of education in most universities (Raja-Hussain, 2004). However, in certain aspects, in several universities surveyed, students were not completely satisfied with e-learning and students were unacquainted with the medium of e-learning (Poon, 2004).

Service quality of e-learning is undoubted one of the most important aspects in higher education institutions. To keep up their reputation and to maintain standard, both public and private institutions of higher learning in Malaysia constantly improving the quality of e-learning services. In order for elearning to be effective, the concerned authorities have to maintain its standards of assured quality in higher education institutions (Inglis 2005; Ehlers \& Pawlowski 2006). Students play a crucial role in providing reliable comments or feedback with regards to the e-learning facilities provided to them and service quality as well as the efficiency of their academic experience through both direct and indirect means.
Students' perceptions are considered as an important element for the improvement of educational services quality. It is nearly impossible to achieve the improvement of educational quality if an e-learning system established without considering students' perceptions (Aghamolaei, Fazel, 2010). Students as the most important consumers in educational context should be taken seriously because their expectations and actual perceptions can affect the sustainability of the higher education institutions (Sahney, Banwet, \& Karunes, 2004). Higher education institutions should also make sure that educational services will meet the students' expectations and it is important if they can exceed those expectations (Brochado, 2009).

\section{E-learning}

\section{LITERATURE REVIEW}

Globally, e-learning has got much more attention from higher education institutions nowadays. With the development of e-learning, various electronic learning tools (e.g. from using e-mail to a virtual learning environment) are introduced which has been causing many changes, especially for the education delivery and support process. As said by Oblinger and Hawkins (2005), numerous educators accept that elearning means: a complete course provided by the faculty is online and the interactions between faculty and students are also online.

According to Dublin (2003), e-Learning is the educational training based on computer while Stockley (2005) stated that e-Learning is the delivery of a learning via electronic means and e-learning includes using computer or electronic devices to provide training, educational or learning materials. In short, e- 
learning is the delivery of a learning, training and education program by electronic means provided by the institutions. E-learning involves the use of a computer or electronic devices in teaching and learning.

\section{Service Quality}

The conception of service quality is complicated. McConnell (2002) defines service quality as performing or fulfilling services beyond customers' expectations or the differences between what customers expected and what they really perceived after receiving the services provided. Another definition was described by Zeithaml and Bitner (2003) which regards service quality as a concentrated assessment which reflects the feeling perceived by customers. O'Neil and Palmer (2004) viewed service quality as the difference between what students want and what they really received.

In educational context, service quality is defined based on the general evaluation of students' experienced based on services provided by the institutions. This is part of students' learning experience which comprised several components of educational services and activities. These activities can happen inside or outside the classroom such as the interactions among students, associates with staffs/teachers of the institution as well as educational facilities (Hossain \& Rahman, 2013). Service quality in this paper refers to the quality level of e-learning provided by institutions, such as the quality of learning content, website design, the process of knowledge delivery and e-learning facilities.

Numerous quality models can be used to improve students' outcomes in education filed, such as Total Quality Management (TQM), ISO 9000, the European Foundation for Quality Management (EFQM) Excellence Model, SERVQUAL model (Parasuraman et al., 1985) as well as American Baldrige National Quality Award. In numerous previous studies, SERVQUAL was widely used to evaluate customer or student perceptions of service quality. Furrer et al. (2000) supported that this measurement has enormous contribution both to the field of academic and marketing. According to Zeithaml, Parasuraman and Berry (1994), SERVQUAL is a common method and can be applied to any service context and situations to assess the quality of services provided. It consists of 21-item scales that measure along five dimensions, namely reliability (5 items), responsiveness (3 items), assurance (4 items), empathy (4 items) and tangibles (5 items).

\section{Students' Satisfaction}

The concept of satisfaction has been used in different field of studies. Oliver (2005) gives the definition of satisfaction as the pleasurable fulfilment, which means consumers perceived that consumption fulfils some need, desire, goal, and that this fulfillment is pleasurable and satisfying. According to Elliot and Healy (2001), student satisfaction can be defined as a temporary attitude that students assess their experienced services provided by educational institutions. Wiers-Jenssen (2002) regards student satisfaction as associated with academic quality because that academic quality is generally measured by student evaluations. On the other hand, Kotler and Clarke (2009), defined students' satisfaction as student's feeling whether the perceived performance meets their expectations.

Many researchers agreed that that there is an interrelation between service quality and students' satisfaction (Bolton \& Drew, 1991; Cronin \& Taylor, 1992; Spreng and Mackoy, 1996; Shemwell, 1998). Ham and Hayduk (2003) also having the same view that a positive correlation exists among service quality and student satisfaction. A study conducted by Wang, Ming-I and Sheih, Chich-Jen (2006) pointed out service quality is related to and positively influences satisfaction.

Petruzzellis, Uggento and Romanazzi (2006) regard service quality is closely related with students' satisfaction. If the services offered by institutions fulfil students' needs, they will feel satisfied and if the services exceed students' needs and expectations, they will extraordinary satisfied. While another negative situation may exist which is services provided by institutions cannot fulfill students' needs. As a result, students will dissatisfy. In the other word, negative impacts will emerge if there is a great deal of difference between perceived service quality and students' expectations.

\section{Students' Expectations and Perceptions}

There are many studies conducted aimed to investigate students' expectations and perceptions on elearning (Wang, 2004). Students' expectations are closely related to students' satisfaction. O'Leary and Quinlan (2007) conducted a study which based on the satisfaction/dissatisfaction theory. The results showed that students expected more on e-learning, while their perceived quality is lower than their expectations and there are many factors that could influenced students' satisfaction. Poon (2004) conducted a study about elearning environment in several selected Malaysian public universities. The results showed that students were not completely satisfied with e-learning. Poon (2004) also assumed that students unacquainted with the medium of e-learning was one of the potential reasons.

A study conducted by Morley (2009) claimed that e-learning has the potential to fulfill students' expectations by addressing their educational problems. His study was conducted at one of the university in Libya and this study showed that students hold high level of expectation on e-learning and they believe that e-learning as an alternative way could offer improvement to their educational problems. Other researchers such as Wu, Tennyson, and Hsia (2010); Jackson, Jones, and Rodriquez (2010), and Osborne, Kriese, Tobey, and Johnson (2009) also investigated studies about student expectations. These authors found that student expectations have great influence on students' satisfaction. Many studies show that students have positive attitudes about learning through online (Stringer \& Thomson, 1998; Wegner, Hollyway, \& 
Garton, 1999; Sandercock \& Shaw, 2000; Spiceland \& Hawkins, 2002).

There are also some researchers who examined the significant differences between students' expectations and perceptions. One of the studies conducted was by Mehdi Ghasemi and Ali kazemi (2012) aimed to investigate the strengths and weaknesses of a service quality system based on students' perceptions with revised SERVQUAL model. The results showed that students' expectations are higher than their perceptions and there was a significant difference between the two. Other researchers such as Sherry, Bhat, Beaver and Ling (2004) use paired t-test to analyze the significant difference between student' expectation and perception. Their study shows the same results as the study conducted by Mehdi Ghasemi and Ali kazemi (2012).

In short, it can be inferred that numerous researchers supported that students' satisfaction is vitally important to institutions of higher learning. Most researchers supported that service quality is related to and positively influences students' satisfaction. Many studies also found that students' expectations and perceptions showed similar results. In addition, some studies about students' expectations, perceptions and their satisfaction claimed that students' expectations and perceptions both have great influences on their satisfaction. Thus, understanding what students expected and what they really experienced are important.

\section{Sample}

\section{METHODS}

The population in this research is 279 sixth semester of undergraduate in a faculty which offered bachelor of education programs in a selected public universities in Malaysia. According to Krejcie and Morgan (1970), 162 students need to be selected from this population as the sample for this study. The faculty offered seven first degree programs, six in education and one non-education program. 162 students were randomly selected from different programs according to the ratio of each program.

Based on the ratio, 20 students were randomly selected from Bachelor of Education in Teaching Malay Language, 16 students were randomly selected from Bachelor of Education in Teaching of English as Second Language, 17 students were randomly selected from Bachelor of Education in Guidance and Counselling, 20 students were randomly selected from Bachelor of Education in Physical Education, 23 students were randomly selected from Bachelor of Education in Agricultural Science, 24 students were randomly selected from Bachelor of Education in Home Science and 42 students were randomly selected from Bachelor of Human Resource Development program.

\section{Measurement}

In this research, the instrument is adapted from Parasuraman (1994). The questionnaires are based on the five dimensions of service quality which are reliability, responsiveness, empathy, tangibility and assurance. English and Malay language were designed to explain those questions. The questionnaire consisting of three parts: personal information, Expectation on Service Quality of e-learning and Perception on service quality of e-learning. The questionnaire is designed to use 5-point Likert scales that makes level of agreement toward a statement: $1=$ strongly disagree; $2=$ disagree; $3=$ neutral; $4=$ agree; and $5=$ strongly agree.

\section{Statistical Methods}

The Cronbach's alpha reliability test is used to measure how consistent and to show how well the items in a set are positively correlated to one another. Descriptive analysis (mean, standard deviation) is conducted to indicate the level of students' expectations and perceptions as well as the gap between them. Paired t-test analysis is performed to test the significant difference between students' expectations and their perceptions.

\section{Reliability Test}

\section{RESULTS}

Cronbach's Alpha of each dimension is greater than 0.70 both for expectation and perception. For expectation, Cronbach's Alpha is 0.882 and for perception, Cronbach's Alpha is 0.716 which are considered to be accepted

\section{Respondents' Profile}

Based on the collected date, shown in Table 1, 127 respondents are female with $83 \%$ and 26 respondents are male with $17 \%$. This means majority of the respondents are female, where female respondents are $66 \%$ more than male respondents. The most dominant age group in this study is between the ages 22 to 24 years old.

This group has 113 respondents with the percentage of 73.9, followed by respondents' age at 25 years old and above which has 32 respondents at $20.9 \%$ and the lowest was age at 19-21 years old which only has 8 respondents at only $3.6 \%$. In addition, there are 127 respondents $(83 \%)$ are Malay, 8 respondents $(5.2 \%)$ are Indian, Chinese respondents are only 5 with the percentage of 3.3 and there are 13 respondents from other countries (Thailand and African Countries).

\section{Descriptive Analysis}

Descriptive analysis is performed to test the level of students' expectations and their perceptions as well as the gap between them. According to data analysis, tangibility records the highest mean score with 4.57 which means students' expectation level towards tangibility is higher than other factors. It is followed by responsiveness and assurance with a little difference which is 4.56 and 4.55 respectively. Empathy and reliability got the lowest mean score which is 4.43 . These five dimensions record the overall mean score of 4.51. This result indicates that the level of students' expectations on service quality of elearning is high.

The findings about the level of students' perceptions show that assurance records the highest 
mean score with 3.37 which means students' perception level towards assurance is higher than other factors. It is followed by tangibility which is 3.33 . Next are responsiveness and reliability in turn. Empathy variable got the lowest mean score which is 3.24. These five dimensions record the overall mean score of 3.30. This result indicates that the level of students' perceptions on service quality of e-learning in the public university is medium.
Through descriptive analysis, the gap between students' expectations and their perceptions is also found out. The results show that the biggest gap between these five dimensions is responsiveness with the gap score -1.28 and tangibility with a short difference afterward (-1.24). On the contrary, the service quality of e-learning has had the best performance in reliability and has gotten the lowest gap score with -0.86 . The details are showed as Table 1 .

Table 1

Gap Scores Related to Each Dimension

\begin{tabular}{|l|c|c|c|}
\hline \multicolumn{1}{|c|}{ Dimensions } & Exp. mean & Per. mean & Gap Score \\
\hline Reliability & 4.13 & 3.27 & -0.86 \\
\hline Responsiveness & 4.56 & 3.28 & -1.28 \\
\hline Assurance & 4.54 & 3.37 & -1.17 \\
\hline Empathy & 4.43 & 3.23 & -1.19 \\
\hline Tangibility & 4.57 & 3.33 & -1.24 \\
\hline Overall & 4.45 & 3.30 & -1.15 \\
\hline
\end{tabular}

\section{Paired T-test}

Paired t-test analysis is used to assess if there is a significant difference between students' expectations and their perceptions. The results show that the 2-tailed Sig. value is 0.000 less than 0.05 , it means that based on all five dimensions at the $95 \%$
(0.05) confidence level there is a significant difference between students' expectation and perception. This result indicates that service quality of e-learning provided by UPM cannot meet students' needs and students are not very satisfied with e-learning system. Table 2 shows the detailed result of the analysis.

Table 2

Result of Paired T-Test

\begin{tabular}{|c|c|c|c|c|c|c|c|}
\hline \multirow{2}{*}{ Sig. (2-tailed) } & \multirow{2}{*}{ Df } & & \multicolumn{3}{|c|}{ Paired Differences (Expectation and Perception) } \\
\cline { 4 - 8 } & & \multicolumn{2}{|c|}{$\begin{array}{c}\text { 95\% Confidence } \\
\text { Interval of the } \\
\text { Difference }\end{array}$} & \multicolumn{2}{|c|}{$\begin{array}{c}\text { Std. } \\
\text { Deviation }\end{array}$} & Mean \\
\hline & & & Upper & Lower & $\begin{array}{c}\text { Std. Error } \\
\text { Mean }\end{array}$ & 18.18 & 25.32 \\
\hline
\end{tabular}

\section{Discussion of Main Findings}

\section{DISCUSSION}

Based on descriptive analysis, the level of expectation towards tangibility is highest than other dimensions. That means students have high expectation on modern learning equipment, visually appealing facilities and learning material as well as the comfortable online learning environment provided by institution of higher learning. Obviously, modern learning equipment such as computer, projector have important influences on e-learning because most of the online learning is based on computers.

Learning materials can reflect students' needs and influence their outcomes, so learning materials are extremely important to students and they must be designed based on students' needs. The university can improve e-learning service quality and fulfill students' expectations according to this finding related to the five dimensions, especially on tangibility, responsiveness and assurance.

Empathy got the lowest score among these five dimensions. This shows that the staff who are responsible to e-learning are not doing well in giving students individual attention, having students' best interests in heart and understanding students' needs. This finding is consistent with previous studies such as studies conducted by Daniel and Berinyuy (2010); Shauchenka, et al. (2010). This finding offers essential insight about students' perceptions of e-learning and it also raised practical considerations for its implementation.

In addition, the finding also shows that the gap is large on all five dimensions which indicates that students have great concerns and are not very satisfied with the service quality of e-learning offered to them. Among the five dimensions, the gap score of reliability is the smallest than others which indicates that the university has better performance in reliability of service dimension in comparison with other dimensions. This finding is consistent with previous studies, such as studies conducted by Hong (2003); Poon (2004); O'Leary and Quinlan (2007). The negative gap scores of all items related to the dimensions obviously show there are adequate opportunities to improve the level of service quality. Gap existence in all dimensions shows the university did not solve students' expectations on service quality of e-learning and also did not perform well in attracting students' confidence about e-learning performance.

Based on paired t-test analysis, there are is a significant difference between students' expectations and perceptions which indicates that service quality of e-learning provided by the university did not meet students' needs and students are not very satisfied with e-learning system. According to the previous studies, the finding was investigated by this study which is 
there is a significant difference between students' expectations and perceptions supports a number of findings in the literature. For example, studies conducted by Ghasemi and Kazemi (2012); Sherry, Bhat, Beaver, and Ling (2004). Student satisfaction is the key factor determining how successful higher education institutions perform their services. Emphasizing on student satisfaction is vitally important to educational institutions not merely because it allows universities to recombine their organizations according to what students really want, but also enables them to develop a supervisory system for helping them fulfill student needs effectively (O’Neill, 2003).

\section{Implications}

Students would be influenced by word-ofmouth communications. Students are not very satisfied and this can have a negative effect on the reputation and sustainability of the university. The aim of quality assurance is to monitor performance against targets and to ensure high-quality output and enhance quality improvements (Harman, 2000). Service quality of elearning provided by the university did not really making the students satisfied. Hence, further improvement on the areas concerns should be initiated.

\section{Recommendations to Improve Service Quality of E- learning}

Firstly, based on the findings of this study, tangibility is more expected by students. So, the university should pay more attention to this dimension. Appropriate investment should be increased to improve tangibility of e-learning service quality. Secondly, the finding of this study also shows that students are expected more on responsiveness and assurance of elearning services. So, learning system needs to be checked and maintained regularly in order to ensuring the system can work well; providing training to staffs; staffs have to improve communication in order to really understand students' needs and expectations.

Thirdly, the finding also shows that gap score of responsiveness is the largest. So, staffs' awareness on responsibility should be enhanced in order to increase their willingness and readiness to help and respond students' requests. Finally, service quality of e-learning assessment should be carried out regularly by authorities of the university. The causes and consequences of assessments of the students should be examined in order to better understand what students expect/want and how much they want and also to know those aspects of service where the university is performing better or worse.

\section{RECOMMENDATIONS FOR FUTURE STUDIES}

Firstly, this study was only conducted in a public university to investigate students' expectations and perceptions on service quality of e-learning. So in future studies, it should be interesting to make a comparison of students expectations level of e-learning between public and private universities considering the fact that tuition fees in public universities are much lower than those in the private universities where students pay higher fees. Secondly, this study was conducted only in one faculty of the selected university. It would be more interesting to measure expectations and perceptions of students from different faculties within the university or even within various universities.

Finally, this study has only focused on the perceptions of the students, considering them as the primary customer in a higher education context. It did not measure the perceptions of other stakeholders in higher education (e.g. academic staff and administrative staff). As Appleton-Knapp and Krentler (2006) point out, different stakeholders have different opinions and it is natural for perceptions to vary between these stakeholder groups. As a result, it is suggested also that future research should consider this context.

\section{REFERENCES}

[1] Aghamolaei, T., \& Fazel, I. 2010. Medical Students' Perceptions of the Educational Environment at an Iranian Medical Sciences University. BMC Med Educ, 10, 87-95.

[2] Ally, M. 2004. Foundations of Educational Theory for Online Learning. In T. Anderson \& F. Elloumi (Eds.), Theory and Practice of Online Learning. Athabasca, Canada: Creative Commons: Athabasca University.

[3] Bolton, R. N., \& Drew, J. H. 1991. A longitudinal Analysis of the Impact of Service Changes on Customer Attitudes. Journal of Marketing, 55, 1-9.

[4] Brochado, A. 2009. Comparing Alternative Instruments to Measure Service Quality in Higher Education. Qual Assur Educ, 17(2), 174-90.

[5] Cronin, J. J. Jr., \& Taylor, S. A. 1992. Measuring Service Quality: A Reexamination and Extension. Journal of Marketing, 56(3), 55-68.

[6] Dublin, L. 2003. If You only Look Under the Street Lamps...... Or Nine e-Learning Myths. The e-Learning Developers Journal, Retrieved July 2005 from http://www.elearningguild.com.

[7] Ehlers, U. D., \& Pawlowski J. M. 2006. Quality in European e-Learning: An Introduction. In Ehlers, U. D., \& Pawlowski, J., (Ed)., Handbook on Quality and Standardisation in E-Learning, pp. 1-13.

[8] Elliot, K. M., \& Healy, M. A. 2001. Key Factors Influencing Student Satisfaction Related to Recruitment and Retention. Journal of Marketing for Higher Education, 10(4), 1-11.

[9] Ham, L., \& Hayduk, S. 2003. Gaining Competitive Advantages in Higher Education: Analyzing the Gap between Expectations and Perceptions of Service Quality. International Journal of Value-Based Management, 16(3), 223-242.

[10] Hanaysha, J., Abdullah, H., \& Warokka, A. 2011. Service Quality and Students' Satisfaction at Higher Learning Institutions: The Competing Dimensions of Malaysian Universities' Competitiveness. The Journal of Southeast Asian Research, 1-10.

[11] Hong, K. S., Lai, K. W., \& Holton, D. 2003. Students' Satisfaction and Perceived Learning with a Webbased Course. Journal of Educational Technology \& Society, 6(1). Retrieved January 15, 2004, from http://ifets.ieee.org/periodical/vol_1_2003/v_1_2003.ht $\mathrm{ml}$.

[12] Inglis, A. 2005. Quality Improvement, Quality Assurance, and Benchmarking: Comparing Two Frameworks for Managing Quality Processes in Open 
and Distance Learning. The International Review of Research in Open and Distance Learning. Retrieved 29 March 2009, from http://www.microsoft.com/isapi/ redir.dll?prd=ie\&pver $=6 \&$ ar $=$ CLinks.

[13] Kim, K.-J., Bonk, C. J., \& Oh, E. J. 2008. The Present and Future State of Blended e-Learning in Workplace Learning Settings in the United States. Performance Improvement, 47(8), 5-16.

[14] Kotler, P., \& Clarke, R. N. 2009. Marketing for Health Care Organizations. Englewood Cliffs, NJ: PrenticeHall.

[15] Krejcie, R. V., \& Morgan, D. W. 1970. Determining Sample Size for Research Activities. Educational and Psychological Measurement, 30(3), 607-610.

[16] McConnell, D. 2002. Negotiation, Identity and Knowledge in e-Learning Communities. Paper Presented at the Networked Learning Conference.

[17] Ministry of Higher Education. 2014. The National Graduate Employability Blueprint 2012-2017. Ministry of Higher Education, Government of Malaysia. Retrived $21 \quad$ March 2018 from www.mohe.gov.my/portal/images/utama/penerbitan/.

[18] O'Neil, M. A., \& Palmer, A. 2004. ImportancePerformance Analysis: A Useful Tool for Directing Continuous Improvement in Higher Education. Quality Assurance Education, 12(1), 39-52.

[19] Oblinger, D. G., \& Hawkins, B. L. 2005. The Myth about E-learning. Educause Review.

[20] O'Leary, Patrick F., and Thomas J. Quinlan Jr. 2007. Learner-Instructor Telephone Interaction: Effects on Satisfaction and Achievement of Online Students. American Journal of Distance Education, 21(3), 13343.

[21] Oliver R. 2005. Quality Assurance and e-Learning: Blue Skies and Pragmatism. Research in Learning Technology, 13, 173-187.

[22] Osborne, R. E., Kriese, P., Tobey, H. and Johnson, E. 2009. And Never the Two Shall Meet? Student vs. Faculty Perceptions of Online Courses. Journal of Educational Computing Research, 40(2), 171-82.

[23] Parasuraman, A., Zeithaml, V. A. and Berry, L. L. 1985. A Conceptual Model of Service Quality and its Implications for Future Research. Journal of Marketing, 49(4), 41-50.

[24] Parasuraman, A., Zeithaml, V. A. and Berry, L. L. 1994. Alternative Scales for Measuring Service Quality: A Comparative Assessment Based on Psychometric and Diagnostic Criteria. Journal of Retailing, 70(3), 20-30.

[25] Petruzzellis, L., D’Uggento, A. M., \& Romanazzi, S. 2006. Student Satisfaction and Quality of Service in Italian Universities. Managing Service Quality, 16(4), 349-364.

[26] Poon, W.C., Low, L.T., \& Yong, G. F. 2004. A study of Web-based Learning (WBL) Environment in Malaysia. The International Journal of Educational Management, 18(6), 374-385.

[27] Raja-Hussain, R. M. 2004. E-learning in Higher Education Institutions in Malaysia. e-mentor, 5(7).

[28] Sahney, S., Banwet, D. K., \& Karunes, S. 2004. Conceptualizing Total quality management in higher education. The TQM magazine. 16(2):145-59.

[29] Sanders, D., \& Morrison-Shetlar, A. 2002. Student Attitudes Toward Web-Enhanced Instruction in an Introductory Biology Course. Journal of Research on Computing in Education, 33(3), 251-262.

[30] Shemwell, D. J., Yavas, U., \& Bilgin, Z. 1998. Customer Service Provider Relationship: An Empirical Test of a Model of Service Quality, Satisfaction and Relationship Oriented Outcomes. International Journal of Service Industry Management, 9(2), 155-168.
[31] Spiceland, J. D., \& Hawkins, P. C. 2002. The Impact on Learning of an Asynchronous Active Learning Course Format. Journal of Asynchronous Learning Networks, 6(1), 68-75.

[32] Spreng, R. A. \& Mackoy, R. D. 1996. An Empirical Examination of a Model of Perceived Service Quality and Satisfaction. Journal of Retailing, 72(2), 52-64.

[33] Stockley, D. 2005. Definition of e-Learning. Retrieved July 22, 2005, from http://derekstockley. com.au/elearning-definition.html.

[34] Stringer, S. B., \& Thomson, J. S. 1998. Evaluating for Distance Learning: Feedback from Students and Faculty (pp. 2-7). ERIC Document Reproduction Service No. ED422879

[35] Wang, M. I., and Sheih, C. J. 2006. The Relationship between Service Quality and Customer Satisfaction: The Example of CJCU. Journal of Information \& Optimization Sciences, 27(1), 193-209.

[36] Wegner, S., Hollyway, K. C., \& Carton, E. M. 1999. The Effect of Internet-Based Instruction on Student Learning. Journal of Asynchronous Learning Networks, 3(2), 1-9.

[37] Wiers-Jenssen, J., Stensaker, B., and Grogaard, J. 2002. Student Satisfaction: Towards an Empirical Deconstruction of the Concept. Quality in Higher Education, 8(2), 183-195.

[38] Zeithaml, V., M., \& Bitner M. 2003. Services Marketing: Integrating Customer Focus across the Firm. Boston, MA: McGraw-Hill. 